\title{
Author Spotlight: Orly N. Farber
}

\section{Orly N. Farber ${ }^{1}$}

Published online: 25 June 2020

(c) Springer Science+Business Media, LLC, part of Springer Nature 2020

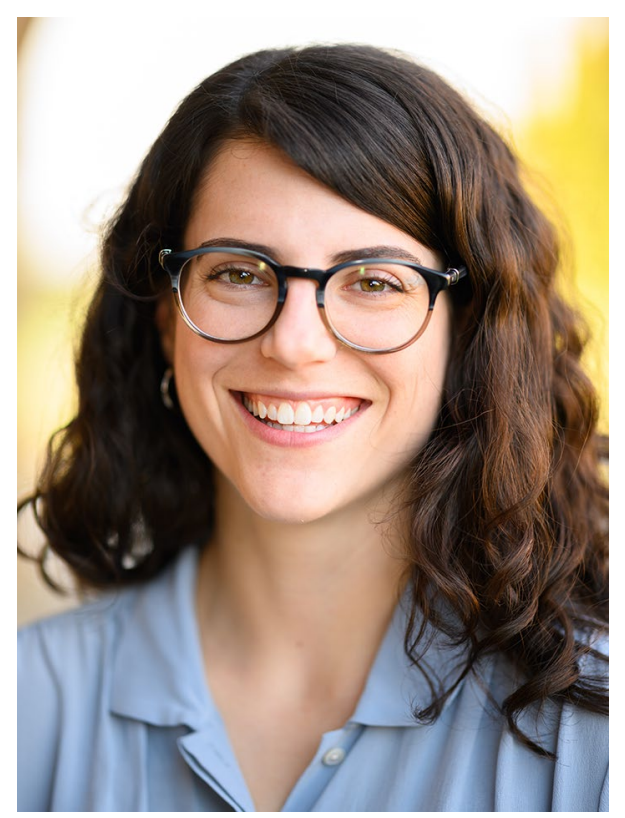

Orly N. Farber is a fourth-year medical student at Stanford University School of Medicine. She completed her undergraduate degree in Comparative Human Development at the University of Chicago and subsequently worked in the Laboratory of Allergic Diseases at the National Institutes of Health as a Postbaccalaureate Intramural Research Training Award recipient. Her interests include general surgery, medical education, and medical journalism. Orly has written for STAT News, published in The Boston Globe, and is a regular contributor to Stanford Medicine's blog Scope.

Publisher's Note Springer Nature remains neutral with regard to jurisdictional claims in published maps and institutional affiliations.

Orly N. Farber

ofarber@stanford.edu

1 Stanford, USA 